\title{
Fetal Kidney Length for Determining Gestational Age in Third Trimester
}

\author{
Gayam S. ${ }^{1}$, Geethavani M. ${ }^{2}$, Paul S. ${ }^{3}$ \\ ${ }^{1}$ Dr. Susheela Gayam, DNB, DGO HOD, ${ }^{2}$ Dr. Geethavani Bai, DGO, ${ }^{3}$ Dr. Sashikala Paul, MD, All authors are affiliated with \\ Department of Obstetrics and Gynaecology, Vijay Marie Hospital \& Educational Society, Khairatabad, Hyderabad, \\ Telangana, India.
}

Corresponding Author: Dr. Susheela Gayam, DNB, DGO HOD, Department of Obstetrics and Gynaecology, Vijay Marie Hospital \& Educational Society, Khairatabad, Hyderabad, Telangana, India. E-mail: sushgayam@yahoo.com

\begin{abstract}
Introduction: Accurate gestational age assessment is important in obstetric care. Ultrasonography plays a significant role in determination of Gestational Age. The ultrasonographic parameters used for GA determination are Crown rump Length, Biparietal diameter, Head circumference, and abdominal circumference and Femur length. Fetal kidney length (FKL) is one of the emerging parameter in estimation of gestational age. Renal length in $\mathrm{mm}$ is identified to approximate the gestational age in weeks. The present study is aimed to corroborate that FKL as a good parameter for gestational age estimation in third trimester. Objective: Is to ascertain the precision of the ultrasonographic 'foetal kidney length' measurement as a reliable parameter for determination of GA in third trimester. Material and Methods: One year Cross-Sectional and an Observational Study was conducted on 171 antenatal women in the third trimester after corroborating the gestational age by first trimester ultra sound and GA by LMP. Ultrasound measurements of Foetal kidney length were taken and correlation with last menstrual period gestational age and with other parameters (BPD, HC, AC, FL) were evaluated. Results: This study showed a good correlation of Mean kidney length with GA by LMP of $(r=0.991)$ than the rest of the parameters, $\mathrm{HC}(\mathrm{r}=0.836), \mathrm{FL}(\mathrm{r}=0.853), \mathrm{AC}(\mathrm{r}=0.853), \mathrm{BPD}(\mathrm{r}=0.734)$ with $\mathrm{p}$ value $=0.000$ for all the parameters. Conclusion: This study confirms that the fetal kidney length measurement is a reliable ultrasonographic parameter for estimating the gestational age accurately in the 3rd trimester and also it is observed that the correlation is increased when used along with other parameters.
\end{abstract}

Keywords: Mean Kidney Length, Accurate Gestational age, Third Trimester, Biparietal diameter, Head Circumference, Abdominal Circumference, Femoral Length.

\section{Introduction}

The essential and primary responsibility of an obstetrician is to date the pregnancy as early as possible during the antenatal period. It is particularly important in high risk pregnancies for example severe preeclampsia, chronic hypertension, severe IUGR, central placenta previa, and sensitized Rh-negative mother where, in some cases early termination may become necessary as soon as fetus becomes mature [1]. Gestational Age estimation is also a prerequisite to interpret certain tests [2] (amniotic fluid assay, serum assay, chorionic villus sampling) and to plan timing of various forms of fetal therapy.

Traditionally the duration of pregnancy is calculated in terms of 9 calendar months and 7 days or 40 weeks or 280 days, calculated from the 1 st day of last menstrual period (LMP) [3]. The fallacy in this method is that the time of ovulation in relation to the menstrual cycle varies greatly

Manuscript received: $10^{\text {th }}$ September 2018
Reviewed: $20^{\text {th }}$ September 2018
Author Corrected: $26^{\text {th }}$ September 2018
Accepted for Publication: $30^{\text {th }}$ September 2018

Obsgyne Review: Journal of Obstetrics and Gynecology both from cycle to cycle and individual to individual. About $10-15 \%$ of pregnant women cannot give their exact LMP and $18 \%$ have significant difference in menstrual and ultrasound dating [4]. Anderson et al [5] demonstrated that only $71 \%$ of women will give their exact LMP. Further, factors such as menstrual abnormalities, lactational amenorrhea, oral contraceptive failure, bleeding in early pregnancy and chronic anovulation [6] multiple gestation, IUGR, diabetic pregnancy, maternal size, variation in fetal lie and engagement as well as inter and intra observer measurement variation 7 may interfere with accurate calculation of Gestational Age.

Ultrasonographic fetal biometry is the most wide spread method used to establish Gestational age [8]. Various sonographic biometric parameters commonly used are Crown Lump Length (CRL), Biparietal diameter (BPD), Head circumference (HC), abdominal circumference (AC) and Femur length (FL). CRL measurements accurately

Available online at: www.medresearch.in 49 | P a g e 
predict Gestational Age to within \pm 5-7 days but can be employed only in cases who present in 1st trimester [9]. In early 2 nd trimester $\mathrm{BPD}, \mathrm{FL}, \mathrm{HC}$ and $\mathrm{AC}$ can predict Gestational Age with fair accuracy $( \pm 10$-11days, $\pm 10-20$ days, \pm 10 -14 days and \pm 10 -14 days respectively [9]. However as the pregnancy advances these parameters become increasingly unreliable in prediction of Gestational Age10 It may be due to biologic variability in the growth of fetuses $[11,12]$. Presently there is no single fetal dimension used for accurate calculation of gestational age in the third trimester. 1 Therefore accurate estimation of Gestational Age in late 2nd and 3rd trimester still remains a problem, especially in women who booked late and unsure about their LMPs [13].

Various non-traditional sonographic parameters for estimating Gestational Age are being studied like transverse cerebellar diameter, fetal foot length, epiphyseal ossification centers, amniotic fluid volume and placental grading, [14] but none of these parameters are proven to correlate with accurate GA in 3rd trimester.

Initially fetal kidney length (FKL) is used for diagnosis of renal malformation in utero and later on it is used for correlation between it and the gestational age. It is strongly correlated to Gestational Age and its linear growth during gestation has been demonstrated on MRI also $[15,16,1]$. It is more accurate method of Gestational Age estimation than BPD, FL, HC and AC after 24th week of gestation $[15,17]$.

\section{Material and Methods}

Place of Study: Dept of Obstetrics \& Gynecology, Vijay Marie hospital \& Educational Society, Hyderabad.

Study Population: Pregnant women in third trimester attending antenatal OP at Vijay Marie hospital.

Type of Study: Cross-Sectional; Observational Study.

Sample Technique: One seventy-one patients

Convenience sampling technique was used.

Study Period: June 2016 - June 2017.

\section{Inclusion Criteria}

1. All patients with singleton pregnancies in the third trimester

2. Patients who were sure of the dates of their last menstrual period

3. Normal antenatal patients with no associated risk factors

4. Women with no history of oral contraception use for at least 3 months before pregnancy

Obsgyne Review: Journal of Obstetrics and Gynecology
Original Research Article

5. Women with all fetal biometric parameters visualized and measured

\section{Exclusion Criteria}

1. Women with Anomalous fetuses

2. Suspected IUGR

3. Unknown dates

4. Multiple Gestations

5. Gestational Diabetics mellitus

6. Foetal Renal pelvic dilatation of $5 \mathrm{~mm}$ or greater

Methodology- The pregnant women in third trimester attending antenatal OPD at Vijay Marie Hospital were enrolled for the prospective study who satisfied the inclusion and exclusion criteria. The selected patients were briefed about the nature of the study, details of the test and a written informed consent was obtained.

Demographic data of the patient was recorded as name, age, occupation, socioeconomic status and obstetric history along with relevant history was recorded on pre designed and pre tested proforma. All women were screened for any complication during pregnancy, any disease e.g., tuberculosis, diabetes mellitus, hypertension, obesity, IUGR and suspected fetal anomalies. Only those fetuses were included in the study in whom the kidneys were clearly visualized and no abnormal renal morphology observed.

One hundred and seventy one pregnant women were subjected for ultrasonographic examination for BPD, HC, $\mathrm{AC}$ and FL and FKL. All measurements were taken during fetal apnoea. When kidneys were visualized just below the stomach in transverse plane, kidneys length was measured and then with 90 degree rotation of probe, the longitudinal axis of kidneys was measured. All these values were compared to the values obtained when all the five parameters i.e. KL, FL, AC, $\mathrm{HC}$ and $\mathrm{BPD}$ were taken together.

\section{Statistical Methods}

1. After collecting the data, Statistical analysis was done by using statistical package for social science (SPSS) 17 th version.

2. Standard deviation taken as measure of variation and the frequencies of the data were expressed as mean $( \pm$ $\mathrm{SD})$.

3. The relationship between fetal kidney length and foetal parameters - BPD, FL, HC and AC was explored by using correlation and regression analysis.

Available online at: www.medresearch.in 50 | P a g e 


\section{Original Research Article}

\section{Results}

Out of 171 pregnant women taken in the study, after considering inclusion and exclusion criteria $9(5.2 \%)$ were in the age group of $<20$ years, $152(88.8 \%)$ were in the age group of 20-30years, $10(5.8 \%)$ were in the age group of $>30$ years. Among them 118 (69\%) were with normal BMI, 44(25.7\%) fall under over-weight group, 9(5.2\%) under Class-1 obesity.

There were 63(36.84\%). Primigravida were 108(63.1\%) and Multigravida were $(>2)$. Dating scan was done in 66 women (38.5\%) between 6-8 weeks, 61(35.6\%) between 8-10weeks, 44 women (25.7\%) between 10-12weeks

BPD: The correlation was best with MKL $(r=0.747)$ and least for $\mathrm{HC}(\mathrm{r}=0.678)$ with all correlations were statistically significant. So with the help of BPD values actual period of gestation can very well be estimated with $r=0.734$.

Table-1: Correlation of BPD with all Parameters

\begin{tabular}{|c|c|c|c|c|c|}
\hline & LMPGA & HC & AC & FL & MKL \\
\hline BPDr & 0.734 & 0.678 & 0.702 & 0.727 & 0.747 \\
\hline P & 0.000 & 0.000 & 0.000 & 0.000 & 0.000 \\
\hline N & 171 & 171 & 171 & 171 & 171 \\
\hline
\end{tabular}

HC: There was an observably good correlation of $\mathrm{HC}$ with Mean kidney length of $(\mathrm{r}=0.840)$ than the rest of the parameters and observed the least correlation with BPD with an $r$ value of 0.678 , but all the correlations were statistically significant.

Table-2: Correlation of HC with all Parameters

\begin{tabular}{|c|c|c|c|c|c|}
\hline & LMP GA & BPD & AC & FL & MKL \\
\hline HCr & 0.836 & 0.678 & 0.768 & 0.767 & 0.840 \\
\hline $\mathrm{P}$ & 0.000 & 0.000 & 0.000 & 0.000 & 0.000 \\
\hline $\mathrm{N}$ & 171 & 171 & 171 & 171 & 171 \\
\hline
\end{tabular}

AC: There was a good correlation of AC with mean kidney length ( $\mathrm{r}=0.864)$ than other parameters FL( $\mathrm{r}=0.863)$, LMP GA $(\mathrm{r}=0.853)$ and moderate correlation with $\mathrm{HC}(\mathrm{r}=0.768)$ and least with $\operatorname{BPD}(\mathrm{r}=0.702)$ with $\mathrm{p}$ value $=0.000$ for all the parameters.

Table-3: Correlation of AC with all parameters

\begin{tabular}{|c|c|c|c|c|c|}
\hline & LMP GA & BPD & HC & FL & MKL \\
\hline AC r & 0.853 & 0.702 & 0.768 & 0.863 & 0.864 \\
\hline P & 0.000 & 0.000 & 0.000 & 0.000 & 0.000 \\
\hline N & 171 & 171 & 171 & 171 & 171 \\
\hline
\end{tabular}

FL: Present study shows the correlation of FL was best with MKL $(r=0.866)$ and least for BPD ( $r=0.678)$. All the correlations were statistically significant.

Table-4: Correlation of FL with all parameters

\begin{tabular}{|c|c|c|c|c|c|}
\hline & LMPGA & BPD & HC & AC & MKL \\
\hline FL $\mathbf{r}$ & 0.853 & 0.727 & 0.767 & 0.863 & 0.866 \\
\hline P & 0.000 & 0.000 & 0.000 & 0.000 & 0.000 \\
\hline N & 171 & 171 & 171 & 171 & 171 \\
\hline
\end{tabular}

MKL: There was a good correlation of Mean kidney length with LMP GA of $(r=0.991)$ than the rest of the parameters and observed the least correlation with BPD with an $\mathrm{r}$ value of 0.747 . With All the correlations were statistically significant. 
Original Research Article

Table-5: Correlation of MKL with all Parameters.

\begin{tabular}{|c|c|c|c|c|c|}
\hline & LMP GA & BPD & HC & AC & FL \\
\hline MKL r & 0.991 & 0.747 & 0.840 & 0.864 & 0.866 \\
\hline P & 0.000 & 0.000 & 0.000 & 0.000 & 0.000 \\
\hline N & 171 & 171 & 171 & 171 & 171 \\
\hline
\end{tabular}

Table-6: Correlation of All Parameters with Gestational Age.

\begin{tabular}{|c|c|c|c|c|c|}
\hline & BPD & HC & AC & FL & MKL \\
\hline GA by LMP r & 0.734 & 0.836 & 0.853 & 0.853 & 0.991 \\
\hline P & 0.000 & 0.000 & 0.000 & 0.000 & 0.000 \\
\hline N & 171 & 171 & 171 & 171 & 171 \\
\hline
\end{tabular}

Thus Kidney length is more reliable to gestational age by LMP.

\section{Discussion}

The first published report of the size of normal fetal kidney length with gestational age sonographically was by Seoys et al [18]. The results of the study by Bertagnoli et al [19] confirmed that measurements of fetal kidney can be used as an additional parameter in routine assessment of fetal wellbeing and also to rule out renal malformations by change in size.

Mahasset et al [20] demonstrated a strong correlation between renal length and gestational age determined by BPD, FL, AC and the average of the three. Hansari et al [21] had also found an excellent correlation between gestational age and FKL, they also found FKL of $29 \mathrm{~mm}$ at 29 weeks, $39.5 \mathrm{~mm}$ at 40 weeks. Rahman et al [22] have also reported mean FKL of $28.8 \mathrm{~mm}$ at 29 weeks and $40.23 \mathrm{~mm}$ at 40 weeks. Lawson et al [23] and Fong and Ryan [24] also reported that measurements of FKL in $\mathrm{mm}$ are approximately the same as gestational age in weeks. Similar results have been reported by Scott et al [25].

Present Study showing Mean kidney length (36.26-1.476) in weeks was found to be more close to LMP derived GA than other multiple parameters (BPD,HC,AC,FL). It also demonstrated FKL best correlation ( $\mathrm{r}=0.991)$ with GA by LMP than other parameters $\mathrm{HC}(\mathrm{r}=0.836), \mathrm{FL}(\mathrm{r}=0.853), \mathrm{AC}(\mathrm{r}=0.853), \mathrm{BPD}(\mathrm{r}=0.734)$ with $\mathrm{P}$ value $=0.000$ for all the parameters. The results of our present study are also in concurrence with the other studies mentioned below.

Nahid yusuf et al study [1] done in 102 pregnant women showed strong correlation among multiple parameters with correlation coefficient $\mathrm{r}=0.99$ for fetal kidney length and gestational age with $\mathrm{P}<0.01$.Konje et al study; [ 15] a prospective two operator study (cross-sectional)done on 73 pregnant women showed correlation coefficient of 0.93 for MKL and GA with $\mathrm{P}<0.002$.

Nahid yusuf et al study, done in 102 pregnant women, Konje et al study, a prospective two operator study (cross-sectional Cohen et al; [16] study done on 397 pregnant women showed correlation coefficient for MKL and GA was 0.82 with $\mathrm{P}<0.001$. Farrokh Seilanian Toosi et al; [26] studied on 89 pregnant women demonstrated a good correlation between LMP GA and FKL,BPD,HC,AC and FL with $\mathrm{P}<0.001$ and also stated that best gestational age predictor can be obtained by combining all parameters with a standard error of 14.2 days. A cross-sectional study done by Monalisa peter et al [27] on 200 pregnant women between 20 weeks to term, demonstrated a linear increase of MKL with GA. Correlation coefficient of 0.95 and $\mathrm{P}<0.001$. Study

Table-7: Correlation Co efficient of Various Studies

\begin{tabular}{|c|c|}
\hline Study Name & r Value \\
\hline Konje et al & 0.93 \\
\hline Cohen et al & 0.82 \\
\hline Nahid yusuf et al & 0.990 \\
\hline Present study & 0.991 \\
\hline
\end{tabular}




\section{Original Research Article}

\section{Conclusion}

Estimation of gestational age is very important in proper obstetric care. With the introduction of high resolution real time ultra sound the ability to image the various organs in utero has dramatically improved. It is said that the 'Renal length in mm approximates the gestational age in weeks'. Many parameters are used to estimate gestational age, but none of them are appropriate especially in third trimester.

Many studies have shown that fetal kidney length can be a good parameter in estimating gestational age in third trimester. This present study too confirms that the fetal kidney length measurement is a reliable ultrasonographic parameter for estimating the gestational age accurately in the 3rd trimester and also it is observed that the correlation increased when used along with other parameters.

A multi centre study could help in formulating reference value for FKL as a new useful parameter for documenting gestational age in 3rd trimester. All the authors have contributed substantially to the conception and design of this study, acquisition of data, analysis and interpretation of data; drafting the manuscript, and revising it critically for publication could

What this study adds to existing knowledge? Through this study, it was concluded that fetal kidney length measurement can be used as a single parameter for estimating gestational age and also its correlation increases when used along with other parameters research.

Consent: Written informed consent was taken from the patients for publication of this research study.

Competing Interests: The authors declare that they have no competing interests.

Funding: Nil, Conflict of interest: Nil

Permission from IRB: Yes

\section{References}

1. Yusuf, N., Moslem, F., \& Haque, J. Fetal Kidney Length: Can be a New Parameter for Determination of Gestational Age in 3rd Trimester. TAJ: Journal Of Teachers Association, 2009;20(2), 147-150. doi:http://dx. doi. org/10.3329/taj.v20i2.3078

2. Pernoll ML, et al. Normal pregnancy and prenatal care. In: Decherney AH, Pernoll ML, editors. Current Obstetric and Gynecologic Diagnosis and Treatment. $8^{\text {th }}$ ed. Fast Norwalk. Appleton and Lange; 1994; 183-201.
3. Grannum P, Bracken M, Silverman R, Hobbins JC. Assessment of fetal kidney size in normal gestation by comparison of ratio of kidney circumference to abdominal circumference. Am J Obstet Gynecol. 1980 Jan 15;136 (2):249-54.

4. Geirsson RT, Busby-Earle RM. Certain dates may not provide a reliable estimate of gestational age. Br J Obstet Gynaecol. 1991 Jan;98(1):108-9.

5. Andersen HF, Johnson TR Jr, Flora JD Jr, Barclay ML. Gestational age assessment. II. Prediction from combined clinical observations. Am J Obstet Gynecol. 1981 Aug 1; 140 (7):770-4.

6. Grudzinskas JG. Assessment of fetal wellbeing in early pregnancy. In: Edmonds D, editor. Dewhurst's Textbook of Obstetrics and Gynaecology for postgraduates. 6th ed. Blackwell science Ltd.; 1999; 133-8.

7. Hadlock FP, et al. Determination of fetal age. In: Athey PA, Hadlock FP, editors. Ultrasound in Obstetrics and Gynaecology. 2nd Ed. New Delhi: B.I. Churchill Livingstone Pvt. Ltd.; 1985; 22-37.

8. Otto C, Platt LD. Fetal growth and development. Obstet Gynecol Clin North Am. 1991 Dec; 18 (4): 90731.

9. MacGregor SN, et al. Assessment of gestational age by ultrasound. Globlibr women's med. 2008. DOI 10.3843/ GLOWM. 10206

10. Benson CB, Doubilet PM. Sonographic prediction of gestational age: accuracy of second- and third-trimester fetal measurements. AJR Am J Roentgenol. 1991 Dec;157(6): 1275- 7. DOI: 10. 2214 / ajr. 157. 6. 1950 881

11. Reece EA, Goldstein I, Pilu G, Hobbins JC. Fetal cerebellar growth unaffected by intrauterine growth retardation: a new parameter for prenatal diagnosis. Am J Obstet Gynecol. 1987 Sep;157(3):632-8.

12. Hill LM, Guzick D, Fries J, et al. The transverse cerebellar diameter in estimating gestational age in the large for gestational age fetus. Obstet Gynecol. 1990 Jun; 75 (6):981-5.

13.Sagi J, Vagman I, David MP, et al. Fetal kidney size related to gestational age. GynecolObstet Invest. 1987;23 (1):1-4. 
14.Gottlieb AG, Galan HL. Nontraditional sonographic pearls in estimating gestational age. SeminPerinatol. 2008 Jun;32(3):154-60. doi: 10.1053/j.semperi.2008.02.003.

15. Konje JC, Abrams KR, Bell SC, Taylor DJ. Determination of gestational age after the 24th week of gestation from fetal kidney length measurements. Ultrasound Obstet Gynecol. 2002 Jun;19(6):592-7.

16. Cohen HL, et al. Normal length of fetal kidneys: sonographic study in 397 obstetric patients. AJR Am J Roentgenol 1991 Sep; 157(3):545-8. DOI: 10.2214/ajr. 157. 3. 1872242

17. Cannie M, et al. Prenatal Magnetic Resonance Imaging Demonstrates Linear Growth of the Human Fetal Kidneys during Gestation. J Urol 2007; 178:1570-74.

18. SeoYS,etal. Normal size of fetal kidneys: Sonographic Measurements.KoreanJObstetGynecol2003;46(3):537- 41

19. Bertagnoli L, Lalatta F, Gallicchio $\mathrm{R}$, et al. Quantitative characterization of the growth of the fetal kidney. J Clin Ultrasound. 1983 Sep;11(7):349-56.

20. Mahesset, et al .Fetal kidney length and gestational age. American Journal of roentology.1999Vol157;545-48.

21. Ansari SM, Saha M, Paul AK, et al. Ultrasonographic study of 793 foetuses: measurement of normal foetal kidney lengths in Bangladesh. AustralasRadiol. 1997 Feb; 41 (1): 3-5.

\section{Original Research Article}

22. Rahman H, et al. Ultrasonographic evaluation of fetal kidney length in third trimester: correlation with gestational age. Bangladesh Journal of Radiology and Imaging 2008;16(1):6-10

23. Lawson TL, Foley WD, Berland LL, Clark KE. Ultrasonic evaluation of fetal kidneys. Radiology. 1981 Jan; 138 (1): 153-6. DOI: 10. 1148/ radiology. 138. 1.74 55076

24. Fong KW,et al. Fetal urogenital tract. In: Rumarck CM, Wilson SR, Carbonean JW, editors. Diagnostic ultrasound. Volume II. 2nd ed. New York: Mosby Year book Inc; 1998; 1069-92.

25. Scott JE, Wright B, Wilson G, et al. Measuring the fetal kidney with ultrasonography. Br J Urol. 1995 Dec;76 (6): 769-74.

26. SeilanianToosi F, Rezaie-Delui H. Evaluation of the normal fetal kidney length and its correlation with gestational age. Acta Med Iran. 2013 May 30; 51 (5): 303-6.

27. Peter M, et al. Fetal kidney length as a parameter for determination of gestational age from 20th week to term in healthy women with uncomplicated pregnancy. Int J Res Med Sci 2017; 5:1869-73.DOI: http://dx. doi.org/ 10.18203/2320-6012.ijrms20171808

\section{How to cite this article?}

Gayam S, Geethavani M, Paul S. Fetal Kidney Length for Determining Gestational Age in Third Trimester.Obs Rev:J obstet Gynecol 2018;4(3):49-54.doi: 10.17511/joog.2018.i03.02. 